\title{
Illness costs to households are a key barrier to access diagnostic and treatment services for tuberculosis in Tajikistan
}

\author{
Raffael Ayé ${ }^{1,2^{*}}$, Kaspar Wyss $^{1,2}$, Hanifa Abdualimova ${ }^{3}$, Sadullo Saidaliev ${ }^{4}$
}

\begin{abstract}
Background: Tuberculosis (TB) control is based on early detection and complete treatment of infectious cases. Consequently, it is important that TB suspects and patients can readily access medical care. This qualitative study investigated determinants of access to DOTS services as identified by patients, health providers and community members in four districts in Tajikistan.

Findings: Focus group discussions were conducted in order to investigate access to TB services. A conceptual framework for access to care guided the analysis. Thirteen focus group discussions involving a total of 97 informants were conducted. Content analysis of discussions and a rating to quantify the relative importance of discussed factors were carried out. The conceptual framework identifies five main components of access to which factors can be assigned: availability, adequacy, acceptability, accessibility and affordability.

Financial factors were considered the most important determinants of access to diagnosis and treatment of tuberculosis. Expenditure for drugs and consultations, for transport, and for special foods as well as lost income were identified as major barriers to treatment. Stigma, doubts about curability and low perceived quality of care were not seen to be significant determinants of access to care for tuberculosis. Community members were well aware of symptoms of tuberculosis and of medical services. These findings were consistent between different respondent groups (community members, patients and providers). They were also highly consistent between the open discussion and the confidential rating.

Conclusions: Illness-costs to households were identified as the main barrier to tuberculosis diagnosis and treatment. To improve access and ultimately adherence to tuberculosis treatment, effective mitigation strategies, e. g. changes in case management, food contributions or financial stimuli, need to be explored and implemented.
\end{abstract}

\section{Background}

Tuberculosis (TB) cases often delay seeking care even when chemotherapy is free of charge[1,2] and defaulting from treatment is frequent. Irregular drug intake and default can lead to further transmission of TB and drugresistance[3]. Some of the countries with the highest rates of drug-resistant $\mathrm{TB}$ are in Central Asia, making treatment adherence even more important in this region [4]. In order for patients to present timely for diagnosis and for TB cases to be able to adhere to the full treatment, access to care is key. In fact, access has been

\footnotetext{
* Correspondence: raffael.aye@birding.ch

'Swiss Tropical and Public Health Institute, Swiss Centre for International Health, Socinstr. 57, 4002 Basel, Switzerland

Full list of author information is available at the end of the article
}

called "the most important determinant of the outcome of treatment of TB"[5].

In many contexts, $\mathrm{TB}$ is linked to stigma and/or perceived to be incurable[6-10]. For those patients believing their illness to have supernatural causes, common sense dictates that they would not utilise biomedical health care. However, in rural Haiti, providing social support had a strong positive influence on adherence, whereas no influence of sorcery beliefs was found[11]. In urban Bolivia, structural barriers including hidden costs of treatment were more important determinants of adherence than socio-cultural factors[12]. TB cases encountered substantial costs already before their diagnosis $[13,14]$, and TB suspects with lower income were less likely to present to a doctor[15]. At large, there are
C Biomed Central

C 2010 Ayé et al; licensee BioMed Central Ltd. This is an Open Access article distributed under the terms of the Creative Commons Attribution License (http://creativecommons.org/licenses/by/2.0), which permits unrestricted use, distribution, and reproduction in any medium, provided the original work is properly cited. 
many factors that potentially influence access to care for TB - which ones are the actual determinants is debated.

Tajikistan has seen the breakdown of the previously comprehensive health system. Health care workers are badly paid and poorly motivated. Often patients have to pay for health services that are stipulated to be free of charge. Tajikistan adopted the DOTS strategy in 2002 and reported 79\% DOTS coverage, 33\% case detection and $84 \%$ treatment success in 2006[16,17]. A study found that patients in Tajikistan face average costs of about 4'900USD purchasing power parity (PPP) per TB episode[18]-in a country with a per capita gross domestic product of 1'300USD PPP at the time of the study [19].

The objective of this study was to identify the factors with the strongest influence on access to tuberculosis services - from the point of view of community members, TB patients and health services providers.

\section{Setting, study population and analytical framework}

The present study received ethical approval from the Ministry of Health of Tajikistan. It was conducted in the four pilot districts of Project Sino, which supported the integration of $\mathrm{TB}$ services into primary care, funded by the Swiss Agency for Development and Cooperation. DOTS implementation in these districts started in 2004 (Danghara and Varzob) and 2005 (Shahrinaw and Tursunzoda). TB laboratory services and treatment are available at DOTS-centres in each district centre. Primary care facilities are allowed to diagnose TB but virtually always refer suspects to the DOTS-centres for diagnosis[1]. Primary care facilities are requested to provide treatment supervision and follow-up if patients do not present for treatment supervision.

We used a previously described analytical framework of access to care in contexts of livelihood insecurity[20]. Our analysis focussed on access and did no go into details of livelihoods. Availability was not covered, as TB services were known to be available at DOTS-centres. The resulting adapted analytical framework organised factors in four categories: accessibility, affordability, acceptability and adequacy. (Table 1). First, content analysis was conducted. Second, the number of statements relating to each of the four categories were summed up and expressed as a percentage along the three respondent groups. There were hardly any statements relating to adequacy and therefore only the other three categories are presented in the results. Third, results of the rating were analysed by calculating the proportion of chickpeas allocated to each factor, whereby each FGD was equally weighted, independent of the number of participants. The four categories from the content analysis were further divided into twelve sub-categories (Table 1).

\section{Focus Group Discussions}

Thirteen focus group discussions (FGDs) were conducted in 2006 to investigate factors influencing access to care for tuberculosis. Five FGDs were conducted with community members, four with TB patients and four with health services providers to cover experiences of stakeholders involved in TB treatment. Stratification along different criteria was used to obtain more valid results (Table 2). Participants were invited by the research team, ensuring different ages were represented.

Table 1 Analytical framework used in this study for factors influencing access to care

\begin{tabular}{|c|c|c|c|c|}
\hline $\begin{array}{l}\text { Main } \\
\text { categories }\end{array}$ & Affordability & Acceptability & Accessibility* & Adequacy* \\
\hline \multirow{5}{*}{$\begin{array}{l}\text { Sub- } \\
\text { categories } \\
\text { (and } \\
\text { examples) }\end{array}$} & $\begin{array}{l}\text { - Missed opportunities (lost income } \\
\text { due to inability to work) }\end{array}$ & - Side effects of treatment & $\begin{array}{l}\text { - Distance to facility (effort } \\
\text { to cover distance, time } \\
\text { needed) }\end{array}$ & $\begin{array}{l}\text { - Organisational } \\
\text { appropriateness of } \\
\text { services }\end{array}$ \\
\hline & $\begin{array}{l}\text { - Medical costs (costs for diagnostic } \\
\text { tests, drugs, etc.) }\end{array}$ & $\begin{array}{l}\text { - Perceived quality of care (technical } \\
\text { specialisation of providers) }\end{array}$ & & $\begin{array}{l}\text { - Physical state and } \\
\text { cleanliness of } \\
\text { facilities }\end{array}$ \\
\hline & $\begin{array}{l}\text { - Non-medical costs (transportation } \\
\text { costs, expenditure for disease-related } \\
\text { diets, etc.) }\end{array}$ & $\begin{array}{l}\text { - Attitude of providers (friendliness } \\
\text { of doctors) }\end{array}$ & & $\begin{array}{l}\text { - Convenient } \\
\text { opening hours }\end{array}$ \\
\hline & & $\begin{array}{l}\text { - Lack of confidentiality (other } \\
\text { community members find out about } \\
\text { TB patient) }\end{array}$ & & \\
\hline & & $\begin{array}{l}\text { - Health beliefs (lack of belief in } \\
\text { curability) }\end{array}$ & & \\
\hline
\end{tabular}

\footnotetext{
†Adapted from reference 20 .
}

*In the participatory approach, factors relating to accessibility and adequacy were not regarded as important (no chickpeas allocated) and the results are presented without these factors. 
Table 2 Eligibility criteria and stratification for the 13 focus group discussions, by respondent category

\begin{tabular}{|c|c|c|}
\hline Community members & Patients & Providers \\
\hline 1) Women from small rural town & 1) Women in treatment & 1) Family doctors from Danghara \\
\hline 2) Men from remote rural village & 2) Men in treatment & 2) Nurses from Varzob \\
\hline 3) Women from rural village & 3) Women and men after treatment success & 3) Family doctors from Shahrinaw and Tursunzoda \\
\hline 4) Men from rural village & 4) Defaulters and patients indicating irregular drug intake & 4) $T B$ specialists from all four districts \\
\hline 5) Women from semi-urban centre & & \\
\hline
\end{tabular}

Community members were invited ad hoc, patients were identified through the TB patient registry and health services providers were identified through staff lists. Information on treatment adherence was incomplete. At the time of invitation, patients were asked whether they had been forced to interrupt treatment at any time. Patients reporting irregular treatment intake were included in the same FGD as defaulters. The research team consisted of a moderator, a transcriber and two observers. The moderator with a background in chemistry, community development and applied sociologic research had previous experience with FGDs and an outstanding ability to gain people's trust and respect.

The FGDs covered the following topics: (i) symptoms and causes of TB, (ii) perceived appropriateness of treatment, (iii) factors determining the communities' ability to receive diagnosis and (iv) to complete treatment for TB. At the beginning of the FGDs with community members no hint to TB was given. Participants were asked about diseases causing cough; subsequently introducing other symptoms like sputum production, fatigue, weight loss, and night sweats. After the discussion on diseases causing the named symptoms, the focus on TB was disclosed to the participants. In FGDs with patients and providers, the focus on $\mathrm{TB}$ was known from the beginning.

After the discussion, participants of community and patient FGDs were asked to rank the factors preventing "people from receiving full medical treatment" by importance in a participatory approach ('rating'), using chickpeas to rank the perceived importance of different factors. No rating was conducted among providers, because it interfered with local concepts of professionalism. For the rating, all factors named during the discussion on access to care were listed. The researchers suggested the following potential factors whenever they were not spontaneously mentioned: attitude of providers, insufficient confidentiality of medical services, stigma of TB, attitude of other community members towards TB patients and lost income. Each participant was asked to confidentially allocate six, three and one chickpea to the three most important factors.

FGDs were conducted in Tajik. Translation to the minority languages Uzbek and Russian were provided by the moderator and an observer as needed. All FGDs were recorded on audiotape and transcribed to English. The accuracy of the transcriptions was checked by the main researcher who is fluent in Tajik and English. Where needed, the whole team re-checked the transcription by listening to the audiotape and by checking their own notes taken during the FGDs. The main researcher read the transcriptions repeatedly, categorised the statements using the analytical framework described above and added codes in TAMS Analyzer (version 3.31b2pt, Matthew Weinstein, 2005).

\section{Study participants}

Fourty-three community members participated in the community FGDs, 21 women and 22 men with a mean age of 42 years. Among providers, 15 doctors, nine nurses and seven TB specialists participated (mean age 45 years). Of 23 patients, eight were women and 15 were men. Participants were mainly from rural areas with about one fourth coming from semi-urban areas.

First the results from the discussion on characteristics of TB and on barriers to treatment are presented and then the relative importance of identified factors from the rating. The topics that came up in the discussion on access to diagnosis and on access to treatment were very much the same. Participants also explicitly stated that the same factors were important at both times. Consequently the results are presented jointly.

\section{Knowledge about TB}

Upon presentation of symptoms of $\mathrm{TB}$, community members mentioned a number of respiratory diseases, most prominently asthma, influenza and bronchitis. Community members also mentioned TB soon in all FGDs. Overall, knowledge of symptoms was accurate. Community members were able to identify medical facilities providing TB treatment in their surroundings.

Knowledge about causes of TB was limited. In particular the belief that TB was inherited and normally incurable was found commonly among community members and also expressed by one patient and one provider. These beliefs were closely linked to the stigmatisation of the illness. The stigma was magnified by the fact that TB services are offered in separate facilities.

Despite the misunderstandings on causes of TB and prospects of care, all respondent groups deemed medical 
treatment necessary and community members stated that they would seek medical care in case of illness. Community members showed themselves well aware of the availability of TB services at the DOTS centres. Overall it was revealed that due to the difficulties associated with accessing medical care, patients tended to delay presenting until their health status had become severe - despite community members being aware of better prospects of cure at earlier presentation to care.

\section{Factors determining access to care}

Respondents in all FGDs agreed that financial factors were the strongest determinants of access to care and the patient's ability to take the full treatment, i.e. adherence. On the question, why people with TB do not get treatment, a woman (teacher, 47 years old) from Varzob town said: "No money, no treatment - money plays a great role." A general practitioner (40 years) from Danghara answered: "First, because of the financial situation, because of the funds." Other possible reasons were not perceived to be equally important. Although stigma of TB was acknowledged, most participants emphasized it would not prevent patients from visiting medical facilities. Side-effects of treatment were experienced by some participating patients, but were not mentioned very often and were considered important by a small minority only.

The perceived higher importance of economic factors relative to acceptability and accessibility of services was also reflected in the number of statements among all respondent groups (Figure 1). Factors relating to adequacy of services were mentioned even less often and are not presented here. Notably, factors relating to acceptability of services were mentioned least often among patients. Financial factors included all direct costs and lost income. Geographical factors included the effort for the patient to travel and time spent travelling. It did not include transport costs and statements linking travel time to money.

Community members allocated $12 \%, 62 \%$ and $20 \%$ of chickpeas to the categories 'missed opportunities', 'medical expenditure' and 'non-medical expenditure' respectively (Figure 2). Patients allocated 21\%, 21\% and 37\% of chickpeas to the same factors. Thus a total of $94 \%$ and $78 \%$ of chickpeas respectively were allocated to financial factors. Factors related to acceptability unified only $11 \%$ and $6 \%$ of chickpeas in patient and community FGDs, respectively, despite the moderator carefully probing for and explaining rational ways of action of these factors.

\section{Factors contributing to costs}

Costs mentioned in the FGDs can be grouped into six categories: diagnosis, drugs and consultation, hospitalisation, transport, increased expenditure for food and lost income. Diagnostic expenditure was seen to be less important with the exception of radiography, which was considered expensive by patients and community members. Cost of drugs and consultation were identified as important barriers by patients and especially by community members (Figure 3). Three patients reported they were asked to pay for the TB drugs. For the majority of patients, 'cost of drugs' stands for additional, symptomatic treatment, like vitamin injections or intravenous rehydration. Admission to hospital has received little attention, probably because there is no admission fee. Admission is however linked to expenditure for transport and increased expenditure for food. Food for hospitalised patients has to be provided by caregivers such as family members leading to higher food-related expenditure during hospitalisation. Participants of the FGDs did

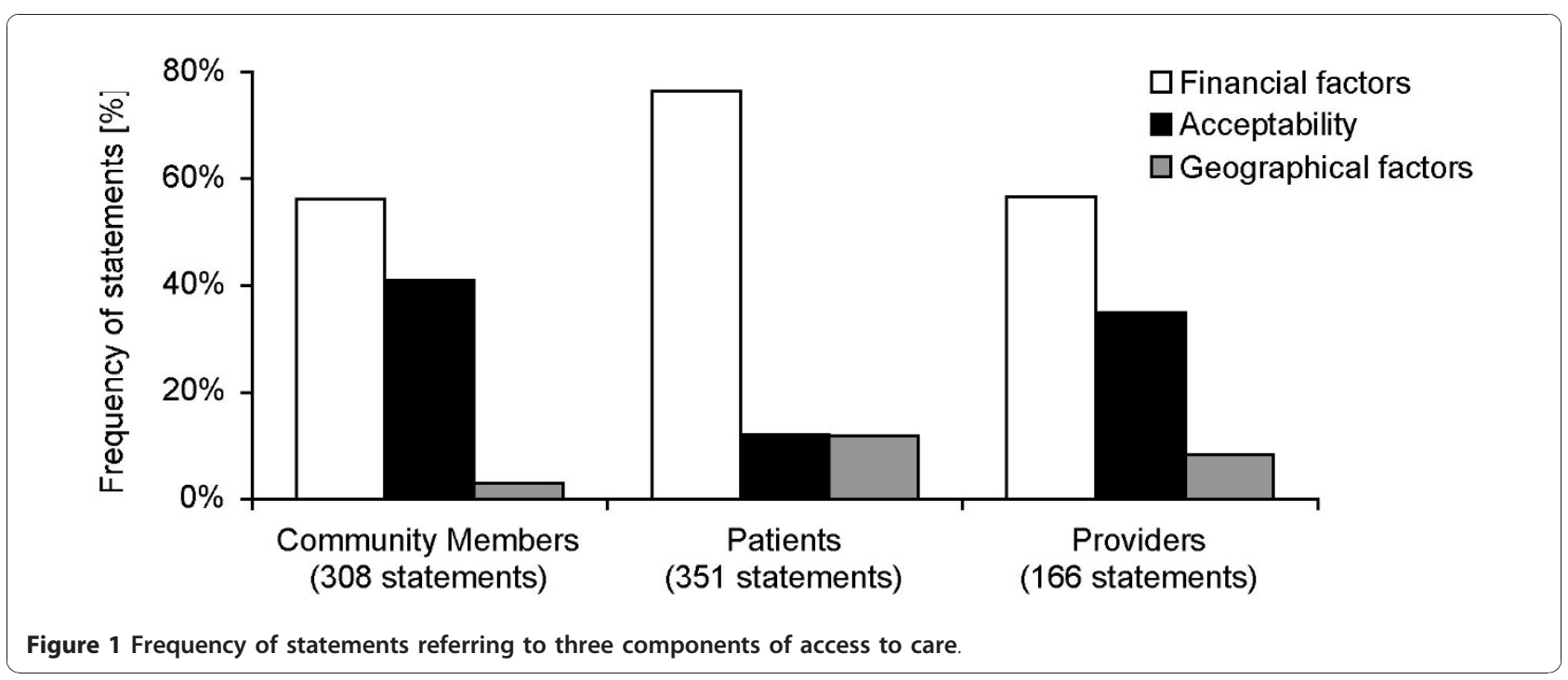




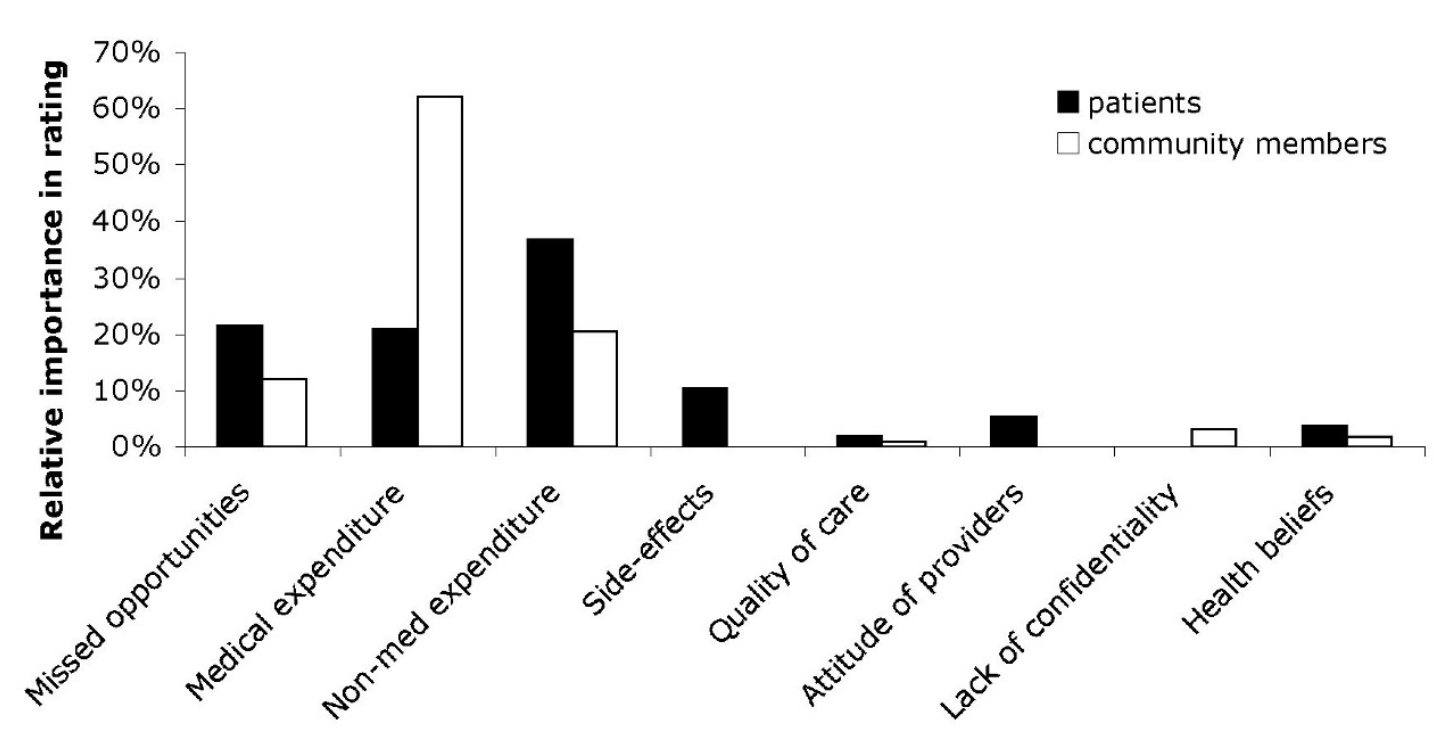

Figure 2 Relative importance of different barriers to tuberculosis treatment, measured by the proportion of chickpeas allocated by participants of FGDs.

not always conceptually separate the costs of travel for food provision from the cost of the food itself.

\section{Significance and implications}

While several studies showed that patients face substantial costs even where TB drugs are stipulated to be free of charge[18,21-24], few previous studies have investigated the relative importance of financial versus other barriers to TB care. We investigated the influence of various health system and household-related factors on access to care for TB in Tajikistan. Community members, patients and providers consistently reported that illness costs to households determine access to diagnosis and treatment to a large extent and deemed quality of

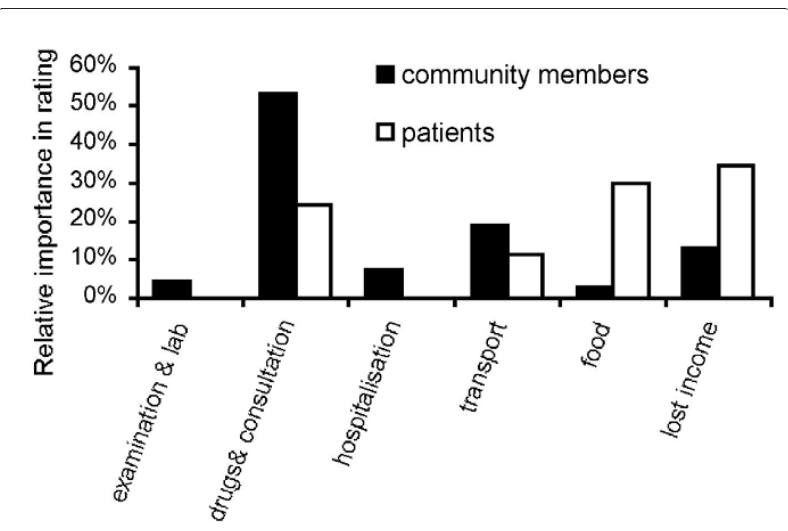

Figure 3 Relative importance of financial factors regarding access to TB services, measured by the proportion of chickpeas allocated by participants of FGDs. care, stigma and other factors less important. To our knowledge, this is the first study to demonstrate that illness-related costs are experienced by a broad range of stakeholders including health care providers as the major determinant of access to TB treatment. It is noteworthy that participants named the same factors as barriers to diagnosis and to treatment. Moreover, they stated that the same factors were important in both situations.

The main limitation of this study is possible reporting bias. Reporting bias, however, should be reduced in the confidential participatory approach. The high consistency between the open discussion and the participatory approach lead us to believe that reporting bias was limited. At the time of study implementation, DOTS was relatively new to two of the study districts. Further improvements may have happened since then.

The predominance of financial factors corresponds well to the results of the small number of previous studies investigating the importance of financial and a wide range of other factors[11,12]. The importance of financial factors is amplified for community members by their lack of awareness about anti-mycobacterial therapy being offered free of charge. This is likely to influence their health care seeking.

Enabling patients to obtain prompt diagnosis and full treatment and thus interrupting the cycle of infection is crucial. The results of this study suggest that doing so requires a reduction of the costs faced by patients and their households.

When designing strategies to reduce costs to patients, it should be kept in mind, that components of access to 
care are interrelated. For example, improvements in the quality and reliability of food provided at the hospital would reduce the need for patients' relatives to travel on a daily basis to bring meals to hospitalised patients. Case management factors, like the provision of additional treatment besides the TB-medication, have been found to cause substantial expenditures for TB patients in Tajikistan[18]. Reviewing the rationality of such additional medication may be needed. For those cases, where the latter is medically warranted, programs and donors should aim at providing additional medication for free, too. The highest costs, however, were related to loss of income due to TB disease[18]. Social support mechanisms including financial stimuli or-as is already being done in Tajikistan-food complements are necessary and may need to be expanded[11,25-27]. Insurance schemes or formalised community support are options to ease the financial hardship of disease, but need to be carefully explored and designed[28]. In the longer term and in contexts with good levels of accountability and governance, such insurance schemes could potentially contribute to improved adherence to TB treatment. Longer delays to TB diagnosis are also associated with higher costs[22,29]. Shortening delays would contribute to lower expenditure as well as a reduction of the loss of income associated with disease.

Concluding, it is difficult to increase TB case detection and treatment adherence as long as patients' immediate concerns are not addressed. For TB control to be successful in Tajikistan and many other countries, programs need to reduce financial barriers to TB treatment. Possible ways to ease the financial hardship of TB for affected households include among others changes in case management, financial stimuli and food supplements.

\section{Acknowledgements}

The authors would like to dedicate this publication to Alisher Jamolovich Rahmonberdiev t, who was a great, thoughtful and sensitive person - and acted as moderator for this study.

This study was conducted in the framework of Project Sino funded by the Swiss Agency for Development and Cooperation, which provided cofunding for the study. We are grateful to all participants for interesting discussions, to Lola Yuldacheva and Zarofat Hamidova who acted as transcriber and observer in the FGDs, to Claudia Sauerborn and Stefanie Granado for input to the qualitative study tools and the analysis and to Kate Molesworth, Helen Prytherch, Christian Auer and Patrick Van der Stuyft for comments on earlier versions of the manuscript.

\section{Author details}

'Swiss Tropical and Public Health Institute, Swiss Centre for International Health, Socinstr. 57, 4002 Basel, Switzerland. 2University of Basel, Basel, Switzerland. ${ }^{3}$ Project Sino, Rudaki prospekt proyezd 5, dom 1, Dushanbe, Tajikistan. ${ }^{4}$ Ministry of Health and Republican Centre for Tuberculosis Control, Bukhoro Street 53, Dushanbe, Tajikistan.

\section{Authors' contributions}

RA was the main responsible researcher for all parts of the study. KW contributed to designing the study and to writing the manuscript. HA and
SS participated in design of the study and data collection. All authors read and approved the final manuscript.

\section{Competing interests}

The authors declare that they have no competing interests.

Received: 26 April 2010 Accepted: 20 December 2010 Published: 20 December 2010

\section{References}

1. Ayé R, Wyss K, Abdualimova H, Saidaliev S: Patient's site of first access to health system influences length of delay for tuberculosis treatment in Tajikistan. BMC Health Serv Res 2010, 10:10.

2. Storla D, Yimer S, Bjune G: A systematic review of delay in the diagnosis and treatment of tuberculosis. BMC Pub Health 2008, 8:15

3. Ormerod L, Prescott R: Inter-relations between relapses, drug regimens and compliance with treatment in tuberculosis. Respir Med 1991, 85:239-242.

4. World Health Organisation: Anti-Tuberculosis Drug Resistance in the World Third Global Report Geneva, World Health Organisation; 2004.

5. Maher D, Nunn P: Evaluation and determinants of outcome of tuberculosis treatment. Bull World Health Organ 1998, 76(3):307-308.

6. Auer C, Sarol J, Tanner M, Weiss M: Health seeking and perceived causes of tuberculosis among patients in Manila, Philippines. Trop Med Int Health 2000, 5:648-656.

7. Sengupta S, Pungrassami P, Balthip Q, Strauss R, Kasetjaroen Y, Chongsuvivatwong V, Van Rie A: Social impact of tuberculosis in southern Thailand: views from patients, care providers and the community. Int J Tuberc Lung Dis 2006, 10(9):1008-1012.

8. Atre S, Kudale A, Morankar S, Rangan S, Weiss M: Cultural concepts of tuberculosis and gender among the general population without tuberculosis in rural Maharashtra, India. Trop Med Int Health 2004, 9:1228-1238.

9. Khan A, Walley J, Newell J, Imdad N: Tuberculosis in Pakistan: sociocultural constraints and opportunities in treatment. Soc Sci Med 2000, 50:247-54.

10. Liefooghe R, Michiels N, Habib S, Moran M, De Muynck A: Perception and social consequences of tuberculosis: a focus group study of tuberculosis patients in Sialkot, Pakistan. Soc Sci Med 1995, 41:1685-92.

11. Farmer $\mathrm{P}$, Robin $\mathrm{S}$, Ramilus $\mathrm{S}$, Kim J: Tuberculosis, poverty and 'compliance': lessons from rural Haiti. Semin Respir Infect 1991, 6:254-260.

12. Greene J: An ethnography of nonadherence: culture, poverty, and tuberculosis in urban Bolivia. Cult Med Psychiatry 2004, 28:401-425.

13. Lambert M, Delgado R, Michaux G, Volz A, Speybroeck N, Van der Stuyft P: Delays to treatment and out-of-pocket medical expenditure for tuberculosis patients, in an urban area of South America. Ann Trop Med Parasitol 2005, 99:781-787.

14. Kemp J, Mann G, Simwaka B, Salaniponi F, Squire S: Can Malawi's poor afford free tuberculosis services? Patient and household costs associated with a tuberculosis diagnosis in Lilongwe. Bull World Health Org 2007, 85:580-585.

15. Zhang $T$, Tang $S$, Jun $G$, Whitehead M: Persistent problems of access to appropriate, affordable TB services in rural China: experiences of different socio-economic groups. BMC Public Health 2007, 7:19.

16. World Health Organisation: Global Tuberculosis Control - Surveillance, Planning, Financing Geneva, World Health Organisation; 2008.

17. World Health Organisation: Global Tuberculosis Control - Epidemiology, Strategy, Financing Geneva, World Health Organisation; 2009.

18. Ayé R, Wyss $K$, Abdualimova $H$, Saidaliev $S$ : Household costs during different phases of tuberculosis treatment in Central Asia: evidence from Tajikistan. BMC Pub Health 2010, 10:18.

19. Central Intelligence Agency: The World Factbook.[https:/wwww.cia.gov/ library/publications/the-world-factbook/geos/ti.html].

20. Obrist B, Iteba N, Lengeler C, Makemba A, Mshana C, Nathan R, Alba S, Dillip A, Hetzel M, Mayumana I, Schulze A, Mshinda H: Access to health care in contexts of livelihood insecurity: a framework for analysis and action. PLoS Med 2007, 4(10):1584-1588.

21. Jackson S, Sleigh A, Wang GJ, Liu XL: Poverty and the economic effects of TB in rural China. Int J Tuberc Lung Dis 2006, 10:1104-1110.

22. Kamolratanakul P, Sawert H, Kongsin S, Lertmaharit S, Sriwongsa J, NaSongkhla S, Wangmanee S, Jittimanee S, Payanandana V: Economic impact 
of tuberculosis at the household level. Int I Tuberc Lung Dis 1999, 3:596-602.

23. Wyss K, Kilima P, Lorenz N: Costs of tuberculosis for households and health care providers in Dar es Salaam, Tanzania. Trop Med Int Health 2001, 6:60-68

24. Russell $\mathrm{S}$ : The economic burden of illness for households in developing countries: a review of studies focusing on malaria, tuberculosis, and human immunodeficiency virus/acquired immunodeficiency syndrome. Am J Trop Med Hyg 2004, 71:147-155.

25. Mohr T, Rajobov O, Maksumova Z, Northrup R: Using Incentives to Improve Tuberculosis Treatment Results: Lessons from Tajikistan Project Hope report, Dushanbe and Millwood; 2005.

26. Jakubowiak W, Bogorodskaya E, Borisov E, Danilova D, Kourbatova E: Risk factors associated with default among new pulmonary TB patients and social support in six Russian regions. Int I Tuberc Lung Dis 2007, 11(8):46-53.

27. Jakubowiak W, Bogorodskaya E, Borisov S, Danilova D, Lomakina O, Kourbatova E: Social support and incentives programme for patients with tuberculosis: experience from the Russian Federation. Int J Tuberc Lung Dis 2007, 11(11):1210-1215.

28. Mclntyre D, Thiede M, Dahlgren G, Whitehead M: What are the economic consequences for households of illness and of paying for health care in low- and middle-income country contexts? Soc Sci Med 2006, 62:858-865.

29. Aspler A, Menzies D, Oxlade X, Banda J, Mwenge L, Godfrey-Faussett P, Ayles $\mathrm{H}$ : Cost of tuberculosis diagnosis and treatment from the patient perspective in Lusaka, Zambia. Int J Tuberc Lung Dis 2008, 12:928-935.

doi:10.1186/1756-0500-3-340

Cite this article as: Ayé et al:: Illness costs to households are a key barrier to access diagnostic and treatment services for tuberculosis in

Tajikistan. BMC Research Notes 2010 3:340.

\section{Submit your next manuscript to BioMed Central} and take full advantage of:

- Convenient online submission

- Thorough peer review

- No space constraints or color figure charges

- Immediate publication on acceptance

- Inclusion in PubMed, CAS, Scopus and Google Scholar

- Research which is freely available for redistribution

Submit your manuscript at www.biomedcentral.com/submit
Biomed Central 